\title{
Additive Manufacturing using Metal 3D Printers
}

\author{
Md Saifur Rahman', Yeasin Miah', Sifat Hasan ${ }^{3}$ \\ CUMT, China ${ }^{1,2,3}$
}

\begin{abstract}
D Printing or Additive manufacturing is a novel method of manufacturing parts directly from digital model by using layer by layer of metal powder infusing or sintering build-up approach. This manufacturing method can produce fully dense metallic parts or less density high durable models in short time compared to subtractive manufacturing from CNC, VMC, turners and lathe machine, with high precision. Features of additive manufacturing like freedom of part design, part complexity, light weighting, part consolidation and design for function are garnering particular interests in metal additive manufacturing for aerospace, oil \& gas, marine and automobile applications. Powder bed fusion, in which each powder bed layer is selectively fused by using energy source like laser, is the most promising additive manufacturing technology that can be used for manufacturing small, low volume, complex metallic parts. This research provides an overview of 3D Printing technologies, materials used for metal 3D printing, applications, advantages, disadvantages, challenges, economics and applications of 3D metal printing technology in India and Bangladesh.
\end{abstract}

Keywords: Additive Manufacturing, 3D Printers, Metal 3D printers, Metal powder, Sintering.

\section{INTRODUCTION}

Additive manufacturing (AM), also known as 3D printing, is a process of joining materials such as plastic, clay, resin and metal powder to make objects from 3D model data, usually layer upon layer, as opposed to subtractive manufacturing methodologies. Main applications of additive manufacturing include rapid prototyping, rapid tooling, direct part production and part repairing of plastic, metal, ceramic and composite materials. The two main parameters of any metal AM process are type of input raw material and energy source used to form the part. Input raw material can be used in the form of metal powder or wire whereas laser/electron beam or arc can be used as energy source.

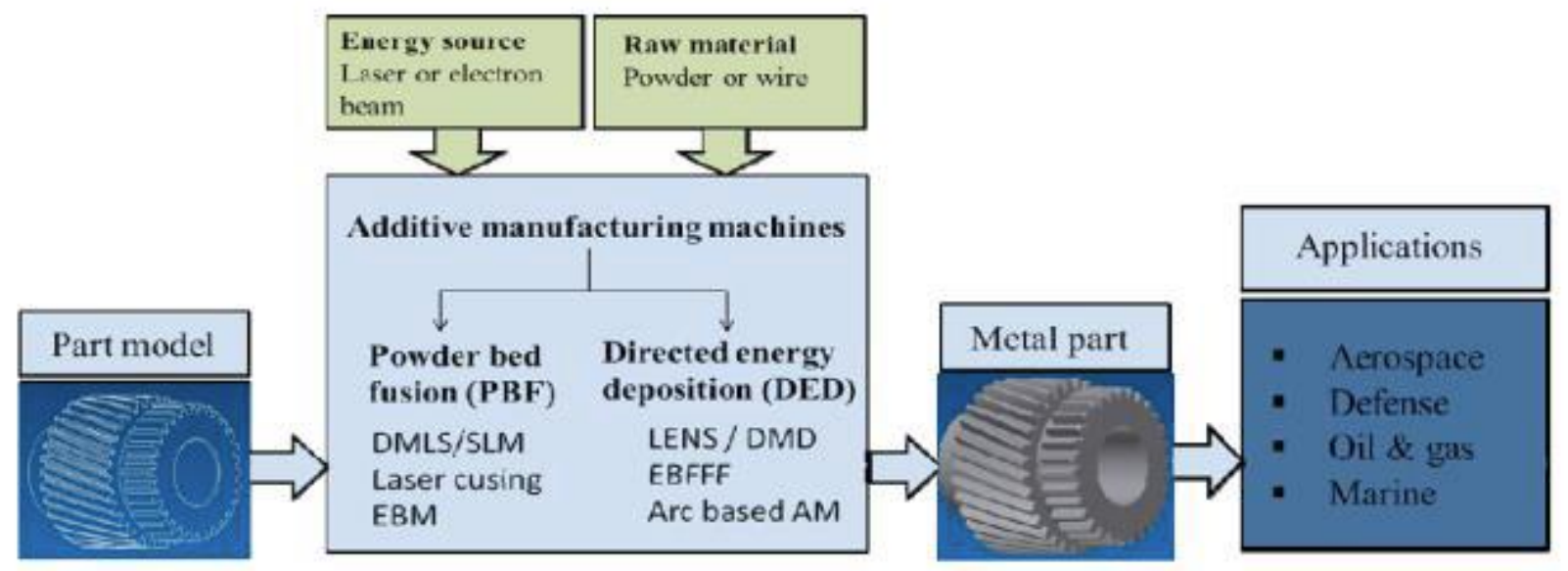

In the 1980s, 3D printing techniques were considered suitable only for the production of functional or aesthetic prototypes, and a more appropriate term for it at the time was rapid prototyping. As of 2019, the precision, repeatability, and material range of 3D printing have increased to the point that some 3D printing processes are considered viable as an industrial-production technology, whereby the term additive manufacturing can be used synonymously with 3D printing. One of the key advantages of 3D printing is the ability to produce very complex shapes or geometries that would be otherwise impossible to construct by hand, including hollow parts or parts with internal truss structures to reduce weight. Fused deposition modelling, or FDM, is the most common 3D printing process in use as of 2020.

3D printable models may be created with a computer-aided design (CAD) package, via a 3D scanner, or by a plain digital camera and photogrammetry software. 3D printed models created with CAD result in relatively fewer errors than other methods. Errors in 3D printable models can be identified and corrected before printing. The manual modelling process of preparing geometric data for 3D computer graphics is similar to plastic arts such as sculpting. 3D scanning is a process of collecting digital data on the shape and appearance of a real object, creating a digital model based on it. 


\section{International Advanced Research Journal in Science, Engineering and Technology}

Vol. 8, Issue 2, February 2021

\section{DOI: $10.17148 / I A R J S E T .2021 .8217$}

CAD models can be saved in the stereolithography file format (STL), a de facto CAD file format for additive manufacturing that stores data based on triangulations of the surface of CAD models. STL is not tailored for additive manufacturing because it generates large file sizes of topology optimised parts and lattice structures due to the large number of surfaces involved. A newer CAD file format, the Additive Manufacturing File format (AMF) was introduced in 2011 to solve this problem. It stores information using curved triangulations.

Before printing a 3D model from an STL file, it must first be examined for errors. Most CAD applications produce errors in output STL files, of the following types:

1. holes;

2. faces normals;

3. self-intersections;

4. noise shells;

5. manifold errors.

A step in the STL generation known as "repair" fixes such problems in the original model. Generally STLs that have been produced from a model obtained through 3D scanning often have more of these errors as 3D scanning is often achieved by point to point acquisition/mapping. $3 \mathrm{D}$ reconstruction often includes errors.

Once completed, the STL file needs to be processed by a piece of software called a "slicer," which converts the model into a series of thin layers and produces a G-code file containing instructions tailored to a specific type of 3D printer (FDM printers). This G-code file can then be printed with 3D printing client software (which loads the G-code, and uses it to instruct the $3 \mathrm{D}$ printer during the $3 \mathrm{D}$ printing process).

Printer resolution describes layer thickness and $\mathrm{X}-\mathrm{Y}$ resolution in dots per inch (dpi) or micrometers ( $\mu \mathrm{m})$. Typical layer thickness is around $100 \mu \mathrm{m}(250 \mathrm{DPI})$, although some machines can print layers as thin as $16 \mu \mathrm{m}(1,600 \mathrm{DPI})$. X-Y resolution is comparable to that of laser printers. The particles (3D dots) are around 50 to $100 \mu \mathrm{m}(510$ to $250 \mathrm{DPI})$ in diameter For that printer resolution, specifying a mesh resolution of $0.01-0.03 \mathrm{~mm}$ and a chord length $\leq 0.016 \mathrm{~mm}$ generate an optimal STL output file for a given model input file. Specifying higher resolution results in larger files without increase in print quality.

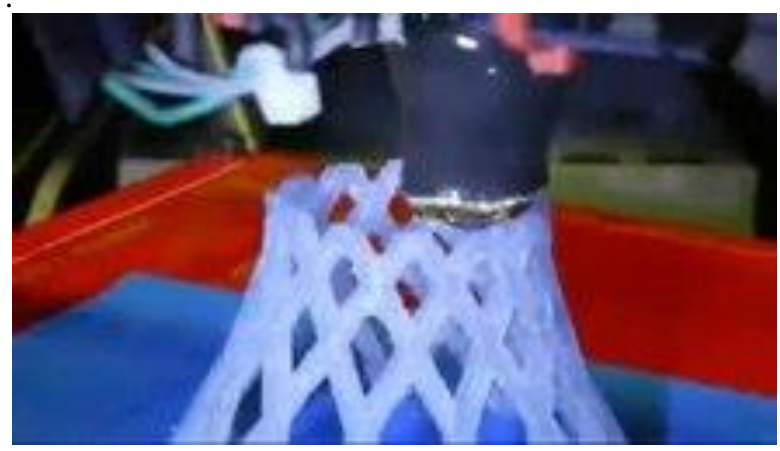

Time-lapse of an 80-minute video of an object being made out of PLA using molten polymer deposition Construction of a model with contemporary methods can take anywhere from several hours to several days, depending on the method used and the size and complexity of the model. Additive systems can typically reduce this time to a few hours, although it varies widely depending on the type of machine used and the size and number of models being produced simultaneously.

Though the printer-produced resolution is sufficient for many applications, greater accuracy can be achieved by printing a slightly oversized version of the desired object in standard resolution and then removing material using a higherresolution subtractive process.

The layered structure of all Additive Manufacturing processes leads inevitably to a stair-stepping effect on part surfaces which are curved or tilted in respect to the building platform. The effects strongly depend on the orientation of a part surface inside the building process.

Some printable polymers such as ABS, allow the surface finish to be smoothed and improved using chemical vapour processes based on acetone or similar solvents.

Some additive manufacturing techniques are capable of using multiple materials in the course of constructing parts. These techniques are able to print in multiple colours and colour combinations simultaneously, and would not necessarily require painting.

Some printing techniques require internal supports to be built for overhanging features during construction. These supports must be mechanically removed or dissolved upon completion of the print.

All of the commercialised metal 3D printers involve cutting the metal component of the metal substrate after deposition. A new process for the GMAW 3D printing allows for substrate surface modifications to remove aluminium or steel. 


\section{DOI: $10.17148 /$ IARJSET.2021.8217}

\section{SLM \& DMLS}

Selective Laser Melting (SLM) and Direct Metal Laser Sintering (DMLS) are two metal additive manufacturing processes that belong to the powder bed fusion 3D printing family. The two technologies have a lot of similarities: both use a laser to scan and selectively fuse (or melt) the metal powder particles, bonding them together and building a part layer-by-layer. Also, the materials used in both processes are metals that come in a granular form.

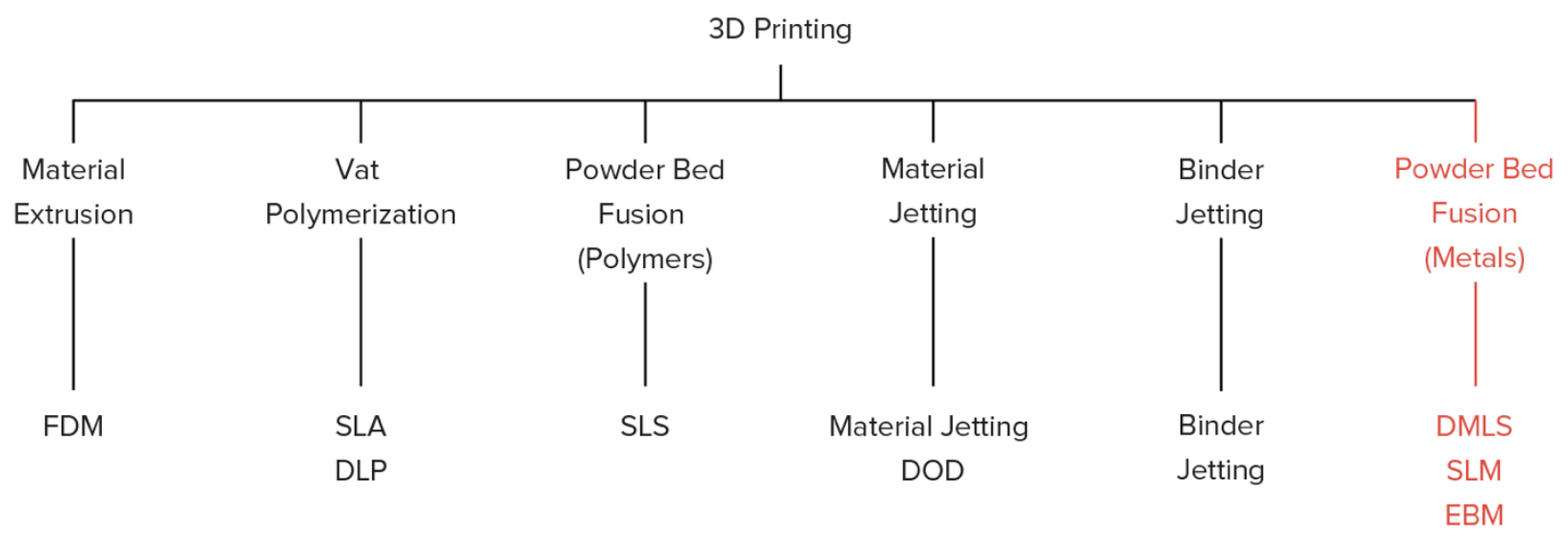

The differences between SLM and DMLS come down to the fundamentals of the particle bonding process: SLM uses metal powders with a single melting temperature and fully melts the particles, while in DMLS the powder is composed of materials with variable melting points that fuse on a molecular level at elevated temperatures.

\section{Essentially:}

SLM produces parts from a single metal, while DMLS produces parts from metal alloys.

Both SLM and DMLS are used in industrial applications to create end-use engineering products.

There are other additive manufacturing processes that can be used to produce dense metal parts, such as Electron Beam Melting (EBM) and Ultrasonic Additive Manufacturing (UAM). Their availability and applications are limited though,
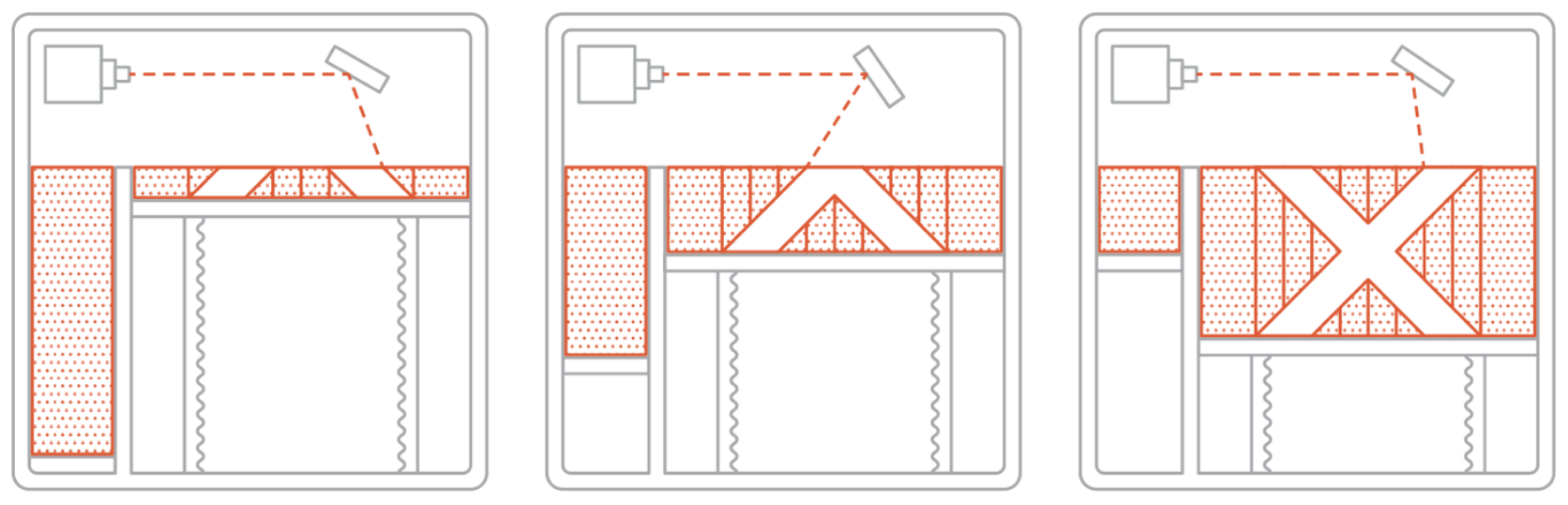

\section{III.HOW DOES A METAL 3D PRINTER WORKS}

The basic fabrication process for SLM and DMLS are very similar. Here is how it works:

1. The build chamber is first filled with inert gas (for example argon) to minimise the oxidation of the metal powder and then it is heated to the optimal build temperature.

2. A thin layer of metal powder is spread over the build platform and a high power laser scans the cross-section of the component, melting (or fusing) the metal particles together and creating the next layer. The entire area of the model is scanned, so the part is built fully solid. 


\section{International Advanced Research Journal in Science, Engineering and Technology}

Vol. 8, Issue 2, February 2021

\section{DOI: $10.17148 / / A R J S E T .2021 .8217$}

3. When the scanning process is complete, the build platform moves downwards by one layer thickness and the recoater spreads another thin layer of metal powder. The process is repeated until the whole part is complete.

When the build process is finished, the parts are fully encapsulated in the metal powder. Unlike polymer powder bed fusion process (such as SLS), the parts are attached to the build platform through support structures. Support in metal $3 \mathrm{D}$ printing is built using the same material as the part and is always required to mitigate the warping and distortion that may occur due to the high processing temperatures.

When the bin cools to room temperature, the excess powder is manually removed and the parts are typically heat treated while still attached to the build platform to relieve any residual stresses. Then the components are detached from the build plate via cutting, machining or wire EDM and are ready for use or further post-processing.

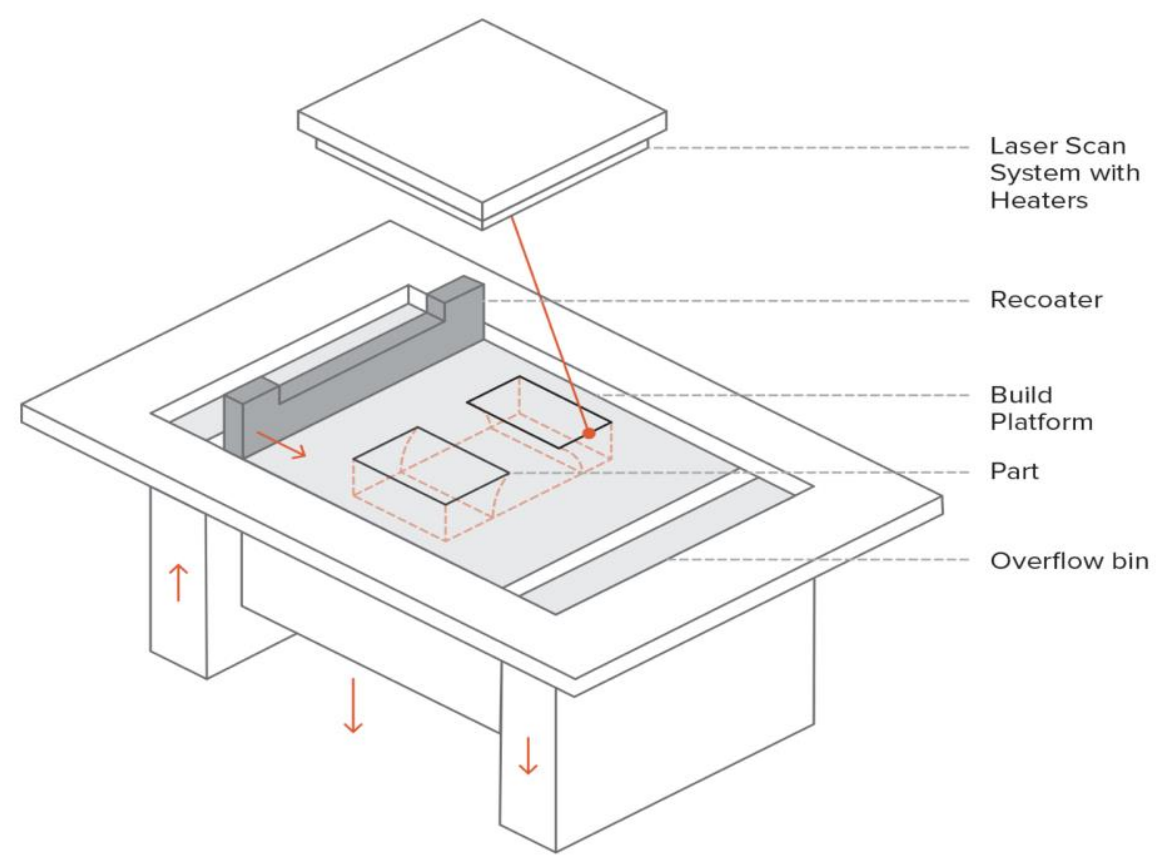

Characteristics of SLM \& DMLS - Printer parameters

In SLM and DMLS almost all process parameters are set by the machine manufacturer. The layer height used in metal 3D printing varies between 20 to 50 microns and depends on the properties of the metal powder (flowability, particle size distribution, shape etc).

The typical build size of a metal 3D printing system is $250 \times 150 \times 150 \mathrm{~mm}$, but larger machines are also available (up to $500 \times 280 \times 360 \mathrm{~mm}$ ). The dimensionally accuracy that a metal 3D printer can achieve is approximately $\pm 0.1 \mathrm{~mm}$.

Metal printers can be used of small batch manufacturing, but the capabilities of metal 3D printing systems resemble more the batch manufacturing capabilities of FDM or SLA machines than that of SLS printers: they are restricted by the available print area (XY-direction), as the parts have to be attached to the build platform.

The metal powder in SLM and DMLS is highly recyclable: typically less than 5\% is wasted. After each print, the unused powder is collected, sieved and then topped up with fresh material to the level required for the next built.

Waste in metal printing though comes in the form of support structure, which are crucial for the successful completion of a build but can increase the amount of the required material (and the cost) drastically. 


\section{International Advanced Research Journal in Science, Engineering and Technology}

Vol. 8, Issue 2, February 2021

DOI: $10.17148 /$ IARJSET.2021.8217

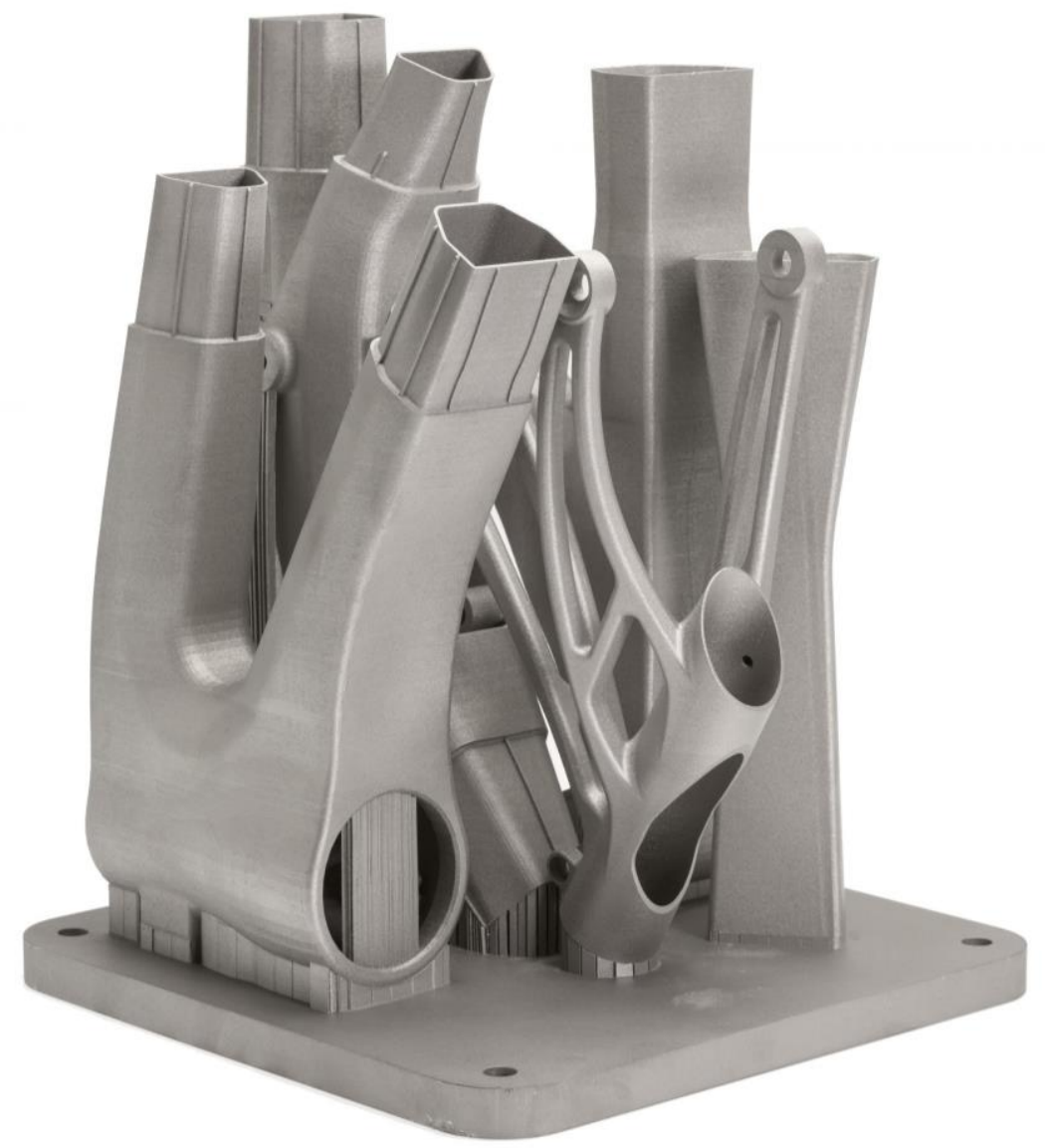

Layer adhesion

Metal SLM and DMLS parts have almost isotropic mechanical and thermal properties. They are solid with very little internal porosity (less than $0.2-0.5 \%$ in the as-printed state and close to none after thermal processing).

Metal printed parts have higher strength and hardness and are often more flexible than parts that are manufactured using a traditional method. However, they are more prone to fatigue.

For example, take a look at the mechanical properties of the AlSi10Mg EOS metal 3D printing alloy and the A360 die cast alloy. These two materials have a very similar chemical composition, high in silicon and magnesium. The printed parts have superior mechanical properties and higher hardness compared to the wrought material.

Due to the granular form of the unprocessed material, the as-built surface roughness ( Ra) of a metal 3D printed part is approximately $6-10 \mu \mathrm{m}$. This relatively high surface roughness can partially explain the lower fatigue strength.

\begin{tabular}{|c|c|c|}
\hline & $\begin{array}{l}\text { AlSi10Mg (3D printing } \\
\text { alloy) }\end{array}$ & A360 (Die cast alloy) \\
\hline Yield Strength (0.2\% strain) * & $\mathbf{X Y}: 230 \mathrm{MPa} \mathbf{Z}: 230 \mathrm{MPa}$ & $165 \mathrm{MPa}$ \\
\hline Tensile Strength * & $\mathbf{X Y}: 345 \mathrm{MPa} \mathbf{Z}: 350 \mathrm{MPa}$ & $317 \mathrm{MPa}$ \\
\hline
\end{tabular}




\section{DOI: $10.17148 / I A R J S E T .2021 .8217$}

\begin{tabular}{l|l|l|}
\hline Modulus * & XY: $: 70 \mathrm{GPa} \mathbf{Z}: 60 \mathrm{GPa}$ & $71 \mathrm{GPa}$ \\
\hline Elongation at break * & $\mathbf{X Y}: 12 \% \mathbf{Z}: 11 \%$ & $3.5 \%$ \\
\hline Hardness ** & $119 \mathrm{HBW}$ & $75 \mathrm{HBW}$ \\
\hline Fatigue Strength ** & & \\
\hline & $97 \mathrm{MPa}$ & $124 \mathrm{MPa}$ \\
\hline
\end{tabular}

*: Heat treated: annealed at 300\&\#8451 for 2 hours **: Tested on as-built samples Support structure \& part orientation

Support structures are always required in metal printing, due to the very high processing temperature and they are usually built using a lattice pattern.

Support in metal 3D printing serves 3 different functions:

- $\quad$ They offer a suitable platform for the next layer to be built upon.

- $\quad$ They anchor the part to the build plate and they prevent warping.

- They act as a heat sink drawing heat away from the part and allowing it to cool at a more controlled rate.

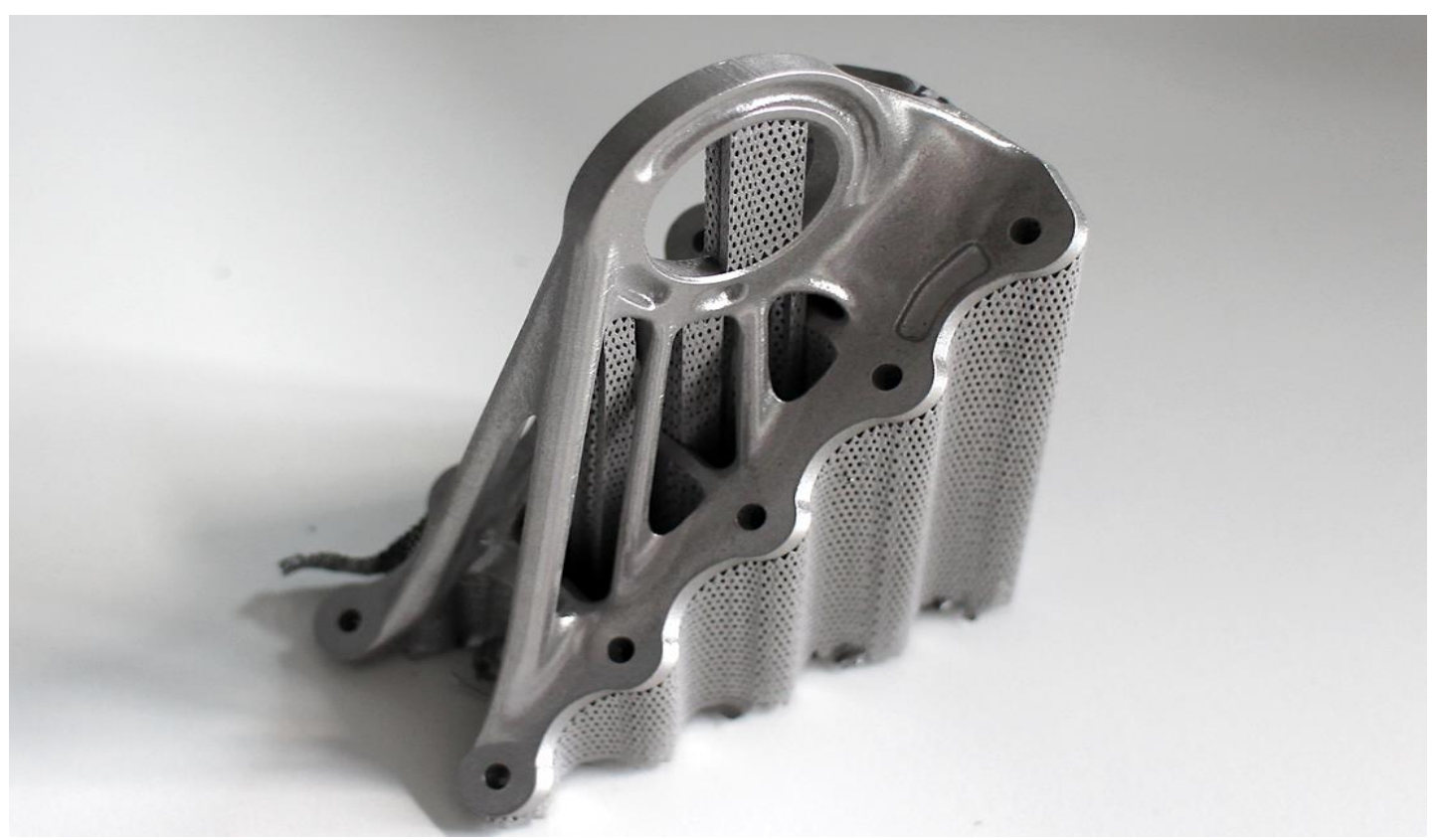

A metal bracket before support removal oriented in a 450 angle.

Parts are often oriented at an angle to minimise the likelihood of warping and maximise part strength in critical directions. However, this will increase the amount of required support, the build time, the material waste and (ultimately) the total cost.

Warping can be also minimised using randomised scan patterns. This scanning strategy prevents the buildup of residual stresses in any particular direction and will add a characteristic surface texture to the part. 


\section{International Advanced Research Journal in Science, Engineering and Technology}

Vol. 8, Issue 2, February 2021

\section{DOI: $10.17148 / I A R J S E T .2021 .8217$}

Since the cost of metal printing is very high, simulations are often used to predict the behaviour of the part during processing. Topology optimisation algorithms are also used not only to maximise the mechanical performance and create lightweight parts but also to minimise the need of support structure and the likelihood of warping.

Hollow sections \& lightweight structures

Unlike polymer powder bed fusion processes like SLS, large hollow sections are not commonly used in metal printing as support structures cannot be easily removed.

For internal channels larger than $\emptyset 8 \mathrm{~mm}$, it is recommended to use diamond or tear-drop cross sections instead of a circular, as they require no support structures.

As an alternative to hollow sections, parts can be designed with skin and cores. Skin and cores are processed using different laser power and scan speed, resulting in different material properties. Using skin and cores is very useful when manufacturing parts with large solid section, as they significantly reduce the print time and the likelihood of warping and produce parts with high stability and excellent surface quality.

Using a lattice structure is also a common strategy in metal 3D printing for reducing the weight of a part. Topology optimisation algorithms can also aid in the design of organic light-weight form.

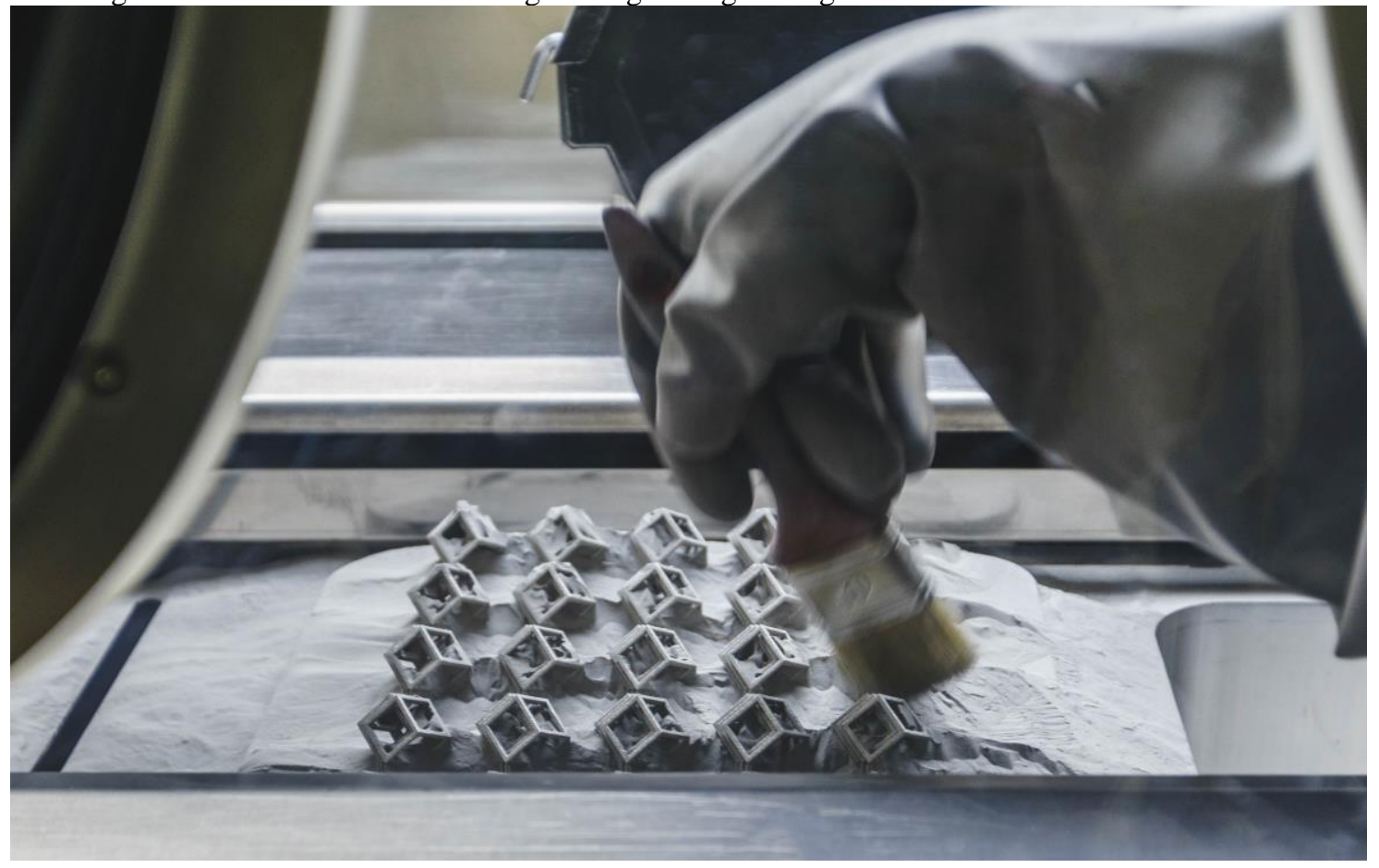

Removing the powder around metal parts produced by the SLM printing process

\section{Common SLM \& DMLS materials}

SLM and DMLS can produce parts from a large range of metals and metal alloys including aluminium, stainless steel, titanium, cobalt chrome and innocent. These materials cover the needs of most industrial application, from aerospace to medical. Precious metals, such as gold, platinum, palladium, and silver can also be processed, but their applications are fringe and mainly limited to jewellery making.

The cost of the metal powder is very high. For example a kilogram of stainless steel 316L powder cost approximately $\$ 350$ - \$450. For this reason, minimising the part volume and the need for support is key to keeping the cost as low as possible.

A key strength of metal 3D printing is its compatibility with high strength materials, such as nickel or cobalt-chrome superalloys, that are very difficult to process with traditional manufacturing methods. Significant cost and time savings can be made, by using metal 3D printing to create a near-net-shape part that can is later post-processed to a very high surface finish. 
International Advanced Research Journal in Science, Engineering and Technology

Vol. 8, Issue 2, February 2021

DOI: $10.17148 /$ IARJSET.2021.8217

\begin{tabular}{|c|c|}
\hline & Material \\
\hline Aluminium alloys & $\begin{array}{l}\text { Good mechanical \& thermal properties } \\
\text { Low density } \\
\text { Good electrical conductivity } \\
\text { Low hardness }\end{array}$ \\
\hline Stainless steel \& tool steel & $\begin{array}{l}\text { High wear resistance } \\
\text { Great hardness } \\
\text { Good ductility and weldability }\end{array}$ \\
\hline Titanium alloys & $\begin{array}{l}\text { Corrosion resistance } \\
\text { Excellent strength-to-weight ratio } \\
\text { Low thermal expansion } \\
\text { Biocompatible }\end{array}$ \\
\hline Cobalt-Chrome superalloys & $\begin{array}{l}\text { Excellent wear \& corrosion resistanc } \\
\text { Great properties at elevated temperatures } \\
\text { Very high hardness } \\
\text { Biocompatible }\end{array}$ \\
\hline Nickel superalloys (Inconel) & $\begin{array}{l}\text { Excellent mechanical properties } \\
\text { High corrosion resistance } \\
\text { Temperature resistant up to } 1200 \mathrm{oC} \\
\text { Used in extreme environments }\end{array}$ \\
\hline
\end{tabular}




\section{DOI: $10.17148 / / A R J S E T .2021 .8217$}

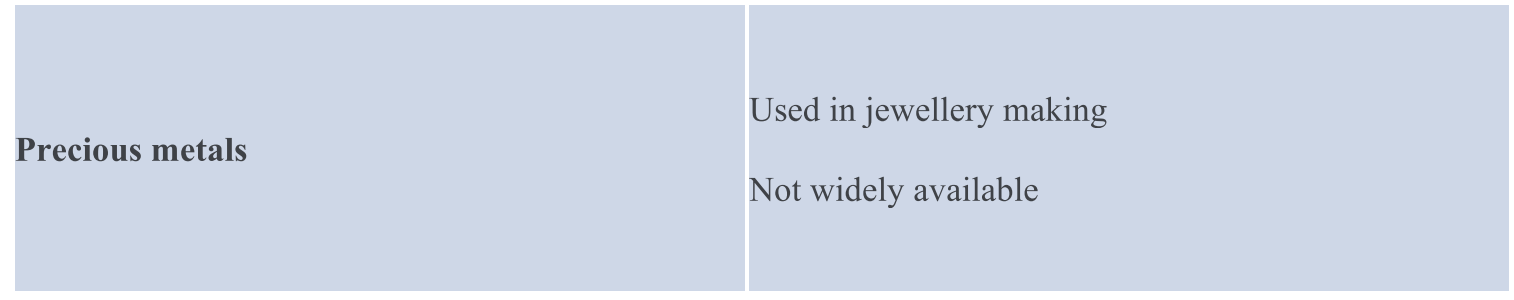

Post processing

Various post-processing techniques are used to improve the mechanical properties, accuracy, and appearance of the metal printed parts.

Compulsory post-processing steps include the removal of the loose powder and the support structures, while heat treatment (thermal annealing) is commonly used to relieve the residual stresses and improve the mechanical properties of the part.

CNC machining can be employed for dimensionally crucial features (such as holes or threads). Media blasting, metal plating, polishing, and micro-machining can improve the surface quality and fatigue strength of a metal printed part.

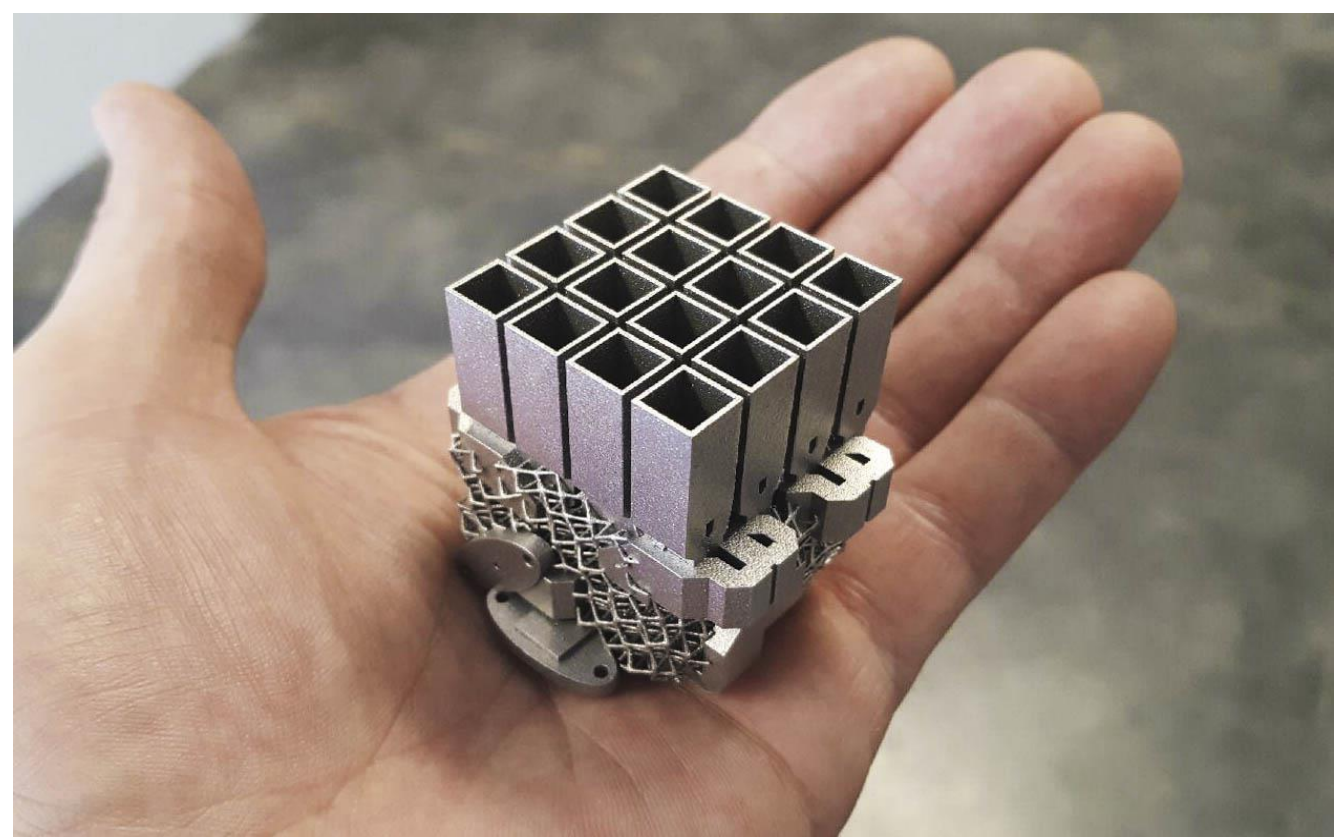

Satellite antenna manufactured using DMLS.

\section{IV.CONCLUSION}

Benefits \& Limitations of Metal 3D Printing

Here are the key advantages and disadvantages of metal 3D printing processes:

Metal 3D printing processes can be used to manufacture complex, bespoke parts with geometries that traditional manufacturing methods are unable to produce.

Metal 3D printed parts can be topologically optimised to maximise their performance while minimising their weight and the total number of components in an assembly.

Metal 3D printed parts have excellent physical properties and the available material range includes difficult to process otherwise materials, such as metal superalloys.

The material and manufacturing costs connected with metal 3D printing is high, so these technologies are not suitable for parts that can be easily manufactured with traditional methods. 


\section{International Advanced Research Journal in Science, Engineering and Technology}

Vol. 8, Issue 2, February 2021

\section{DOI: $10.17148 / / A R J S E T .2021 .8217$}

The build size of the metal 3D printing systems is limited, as precise manufacturing conditions and process control are required.

Already existing designs may not be suitable for metal 3D printing and may need to be altered.

Detailed design guidelines form metal 3D printing are given in this article of the Knowledge Base. The main characteristics of SLM and DMLS systems are summarized in the table below:

\begin{tabular}{|c|c|}
\hline & Metal 3D printing (SLM / DMLS) \\
\hline Materials & Metals \& metal alloys (aluminium, steel, titanium etc) \\
\hline Dimensional accuracy & $\pm 0.1 \mathrm{~mm}$ \\
\hline Typical build size & $250 \times 150 \times 150 \mathrm{~mm}$ (up to up to $500 \times 280 \times 360 \mathrm{~mm}$ ) \\
\hline Common layer thickness & $20-50 \mu \mathrm{m}$ \\
\hline Support & Always required \\
\hline
\end{tabular}

Rules of thumb

- Metal 3D printing is most suitable for complex, bespoke parts that are difficult or very costly to manufacture with traditional methods.

- $\quad$ Minimising the need for support structures will greatly reduce the cost of metal printing.

- Topology optimisation is essential for maximising the added benefits of using metal printing.

- Metal 3D printed parts have excellent mechanical properties and can be manufactured from a wide range of engineering materials, including metal superalloys.

Metal 3D printers has a major role in developing countries such as India, Bangladesh and Pakistan. These Indian Sub continent countries are the fastest developing economies in the world with the focus on manufacturing sector. India being the hub for car manufacturing and castings of automotive parts. Bangladesh is turning out to be a new world leader in textile manufacturing and has show exemplary progress in casting sector. With average GDP growth of 5\%> the 3D printers are finding their way in the manufacturing industry, Health industry(dentals and prosthetics), Research and Development and aerospace industry. 
International Advanced Research Journal in Science, Engineering and Technology

Vol. 8, Issue 2, February 2021

\section{DOI: $10.17148 /$ IARJSET.2021.8217}

\section{REFERENCES}

1: Alec 2016, 3D Systems completes GE aircraft bracket challenge with metal 3D printing solution, www.3ders.org/articles/20160505-3d-systemscompletes-ge-aircraft-bracket-challenge-with-metal-3d-printing-solution.html

2: Allen, J. 2015, An Investigation into the Comparative Costs of Additive Manufacture vs. Machine from Solid for Aero Engine Parts, www.researchgate.net/publication/266164765 RTO-MP-AVT

3: Alvarez, P. 2014, Metal powder and Design Key elements for SLM process, Dissemination workshop of Merlin FP7 project, IK4, Lortek, Ordizia, December 2014 Berger 2013, A game changer for the manufacturing industry? Additive manufacturing - Roland Berger, Strategic Consultants, Munich, November 2013

4: Bhavar et al., 2014, A Review on Powder Bed Fusion Technology of Metal Additive Manufacturing, 4th International conference and exhibition on Additive Manufacturing Technologies-AM-2014, September 1\&2, 2014, Bangalore, India.

5: Electron beam 2016, Wikipedia, https://en.wikipedia.org/wiki/Electron_beam_freeform_fabrication

6: EOS 2016,_EOS Machines Technical data Sheet - http://www.eos.info/systeme_loesungen/metall/systeme_und_zubehoer

7: EOS 2016-1, Material data Sheet - Stainless Steel 316L, http://www.eos.info/werkstoffe-m

8: GE Newsroom 2015, GE Oil \& Gas Uses 3D Printing to Produce Control Valve Parts at Kariwa Plant www.genewsroom.com

9: Gratton, A. 2012, Comparison of Mechanical, Metallurgical Properties of 17-4PH Stainless Steel between Direct Metal Laser Sintering (DMLS) and Traditional Manufacturing Methods, Proceedings of The National Conference On Undergraduate Research (NCUR) 2012, Weber State University, Ogden Utah March $29-31,2012$

10: Herderick, E. , 2011, Additive Manufacturing of Metals: A Review, Materials Science and Technology (MS\&T) 2011, October 16-20, 2011, Columbus, Ohio

11: Kruth, J.P. et al 2010, Part and material properties in selective laser melting of metals, 16th International Symposium on Electromachining (ISEM XVI) Shanghai, China 201

12: Norsk 2016, Norsk Titanium announces \$10M investment from Harbert European Growth Capital Fund, www.3ders.org/articles/20160526-norsktitanium-announces-investment-from-harbert-european-growth-capital-fund.html

13: Met 2016, The DMLS Technology www.e-manufacturing.it

14: Morris, G. 2014, Additive Manufacturing at GE-www.gecapital.com/webinar-assets/pdf/3dprinting-capital.pdf

15: Paul. P. 2015, Norsk Titanium 2016, 3D-Druck von Flugzeugteilen ist Realität, www.3d-drucken.de/2015/12/norsk-titanium-3d-druck-vonflugzeugteilen-ist-realitaet/

16: Slotwinski, J.A. 2013, Materials Standards for Additive Manufacturing. PDES, Inc. Workshop March 14, 2013 NIST Engineering Laboratory

17: Surel, A. 2008, Direct Metal Laser-Sintering (DMLS), Avec l'EOSINT M 270, Eighteenth International Conference \& Exhibit - Molding 2008, Feb 18-20, 2008, San Francisco, California, USA 